\title{
Endoscopic Diagnosis and Differentiation of Inflammatory Bowel Disease
}

\author{
Ji Min Lee and Kang-Moon Lee \\ Department of Internal Medicine, St. Vincent's Hospital, College of Medicine, The Catholic University of Korea, Suwon, Korea
}

Patients with inflammatory bowel disease have significantly increased in recent decades in Korea. Intestinal tuberculosis (ITB) and intestinal Behcet's disease (BD), which should be differentiated from Crohn's disease (CD), are more frequent in Korea than in the West. Thus, the accurate diagnosis of these inflammatory diseases is problematic in Korea and clinicians should fully understand their clinical and endoscopic characteristics. Ulcerative colitis mostly presents with rectal inflammation and continuous lesions, while CD presents with discontinuous inflammatory lesions and frequently involves the ileocecal area. Involvement of fewer than four segments, a patulous ileocecal valve, transverse ulcers, and scars or pseudopolyps are more frequently seen in ITB than in CD. A few ulcers with discrete margins are a typical endoscopic finding of intestinal BD. However, the differential diagnosis is difficult in many clinical situations because typical endoscopic findings are not always observed. Therefore, clinicians should also consider symptoms and laboratory, pathological, and radiological findings, in addition to endoscopic findings. Clin Endosc 2016;49:370-375

Key Words: Inflammatory bowel diseases; Colitis, ulcerative; Crohn disease; Endoscopy; Diagnosis, differential

\section{INTRODUCTION}

Inflammatory bowel disease (IBD) is a chronic and idiopathic inflammatory disease of the digestive tract showing a remitting and relapsing disease course. Ulcerative colitis (UC) and Crohn's disease (CD) are two major forms of IBD. The number of patients with IBD has rapidly increased in recent years and is increasingly prominent in Korea. ${ }^{1}$ However, many clinicians do not yet fully understand the clinical and endoscopic characteristics of IBD so that diagnosis is frequently delayed or incorrect in many cases. Accurate diagnosis of IBD is an important problem in Korea due to the higher prevalence of intestinal tuberculosis (ITB) and intestinal Behcet's

Received: June 28, 2016 Revised: July 18, 2016

Accepted: July 20, 2016

Correspondence: Kang-Moon Lee

Department of Internal Medicine, St. Vincent's Hospital, College of Medicine, The Catholic University of Korea, 93 Jungbu-daero, Paldal-gu, Suwon 16247, Korea Tel: +82-31-249-8151, Fax: +82-31-253-8898, E-mail: drmaloman@catholic.ac.kr

(c) This is an Open Access article distributed under the terms of the Creative Commons Attribution Non-Commercial License (http://creativecommons.org/ licenses/by-nc/3.0) which permits unrestricted non-commercial use, distribution, and reproduction in any medium, provided the original work is properly cited. disease (BD) than in the West. ${ }^{2,3}$

Guidelines for diagnosis of IBD were established by the IBD Study Group of the Korean Association for the Study of Intestinal Diseases in $2009^{3-6}$ In this review, we delineate typical endoscopic findings and the differential diagnostic features of $\mathrm{UC}, \mathrm{CD}$, ITB, and intestinal BD based on these guidelines.

\section{TYPICAL ENDOSCOPIC FINDINGS OF INFLAMMATORY BOWEL DISEASE}

\section{Ulcerative colitis}

The inflammation involves the rectum in most cases and spreads proximally. The typical endoscopic findings in patients with UC include edematous mucosa, erythema, loss of vascular markings, and mucosal friability. ${ }^{4}$ More severe cases may be associated with erosions, ulcers, and spontaneous bleeding. Luminal narrowing and pseudopolyps may occur due to chronic inflammation, which results in mucosal atrophy (Fig. 1). ${ }^{7-9}$ Focal inflammation around the appendiceal orifice is observed in up to $75 \%$ of patients with UC. ${ }^{10}$

However, these typical findings are not always present. A 

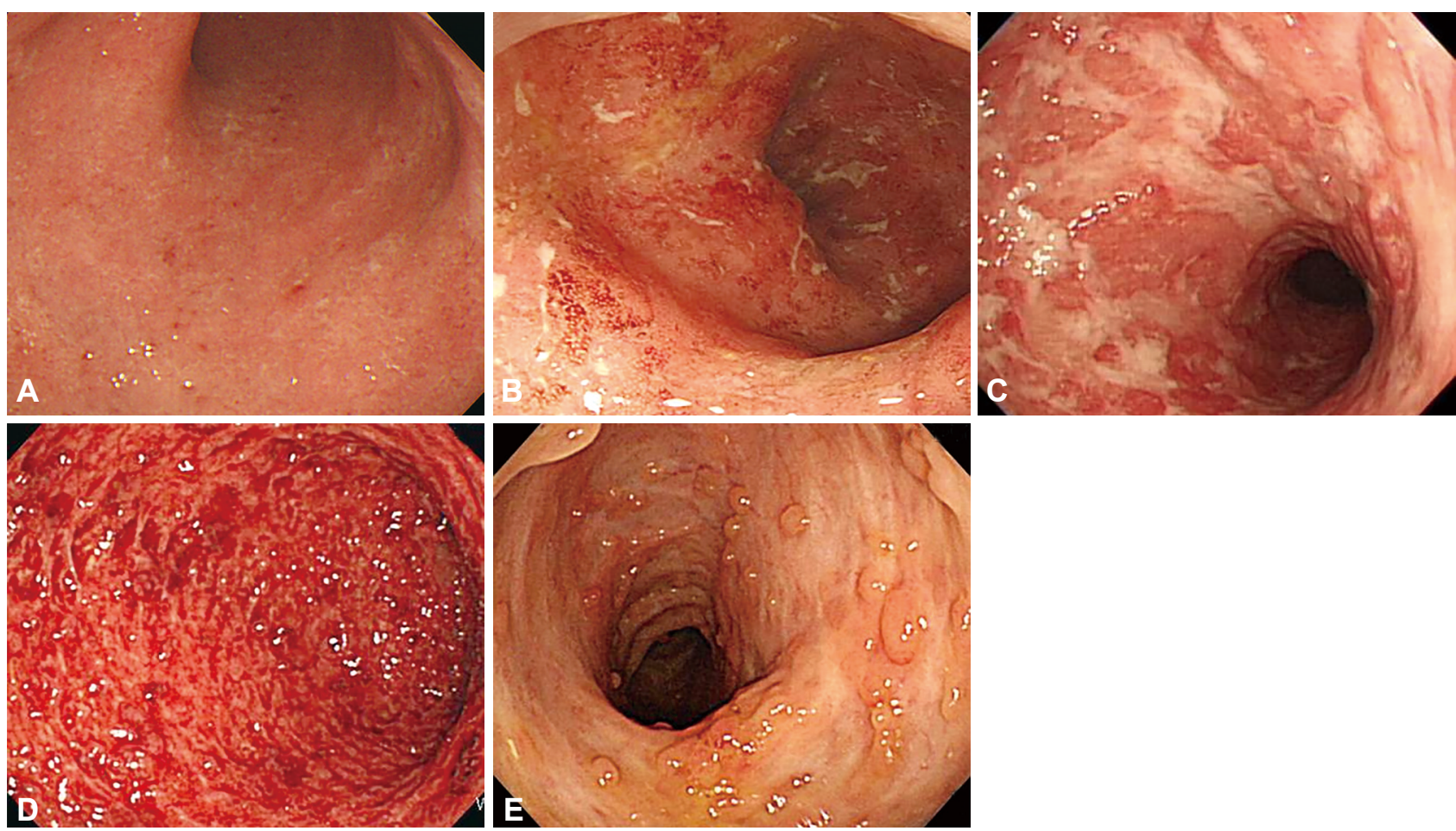

Fig. 1. Typical endoscopic features of ulcerative colitis. (A) Mild: mucosal erythema, fine granularity, decreased vascular marking. (B) Moderate: marked erythema, loss of vascular marking, erosions. (C) Severe: ulcers. (D) Severe: spontaneous bleeding. (E) Luminal narrowing with pseudopolyps.
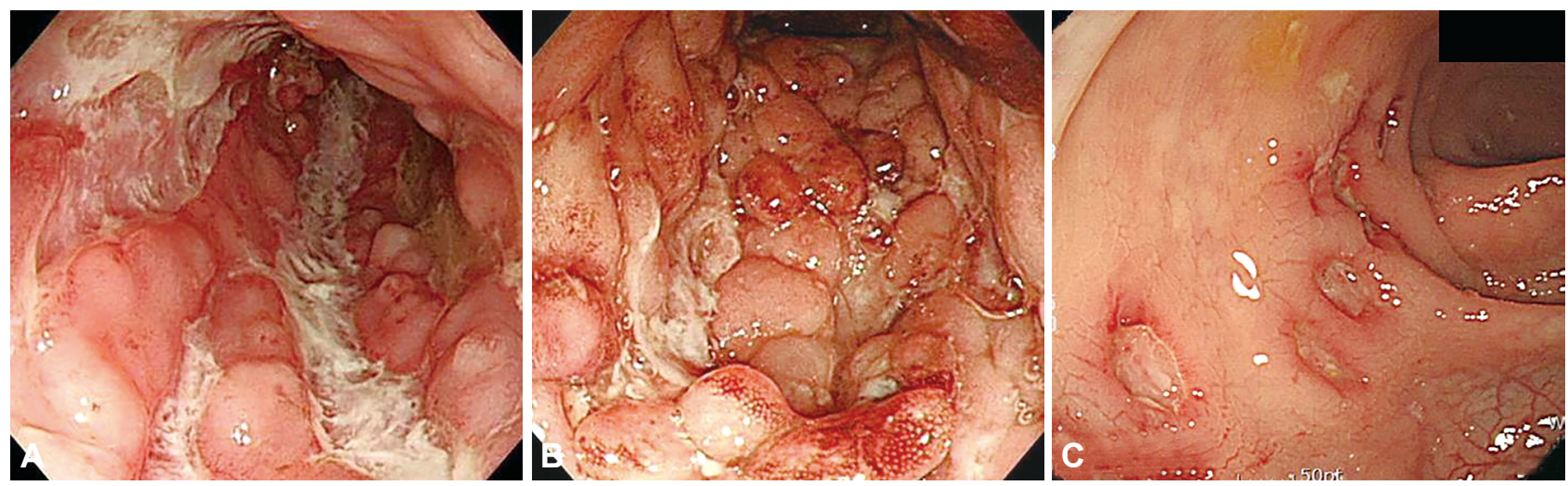

Fig. 2. Typical endoscopic features of Crohn's disease. (A) Longitudinal ulcers, (B) cobblestone appearance, (C) aphthous ulcers showing longitudinal array.

Korean study revealed that atypical distribution of inflammation was seen in $20 \%$ of newly diagnosed UC patients during initial colonoscopy: $3.3 \%$ had segmental UC with rectal sparing and $15.8 \%$ presented with segmental skip lesions without appendiceal orifice inflammation. ${ }^{11}$ Although inflammation in UC patients is mostly limited to the colon, ileal inflammation (backwash ileitis) may infrequently be observed. ${ }^{12}$ In this case, physicians should consider small bowel evaluation to differentiate $\mathrm{CD}$ from UC.13

\section{Crohn's disease}

Typical endoscopic findings in CD include discontinuous distribution of longitudinal ulcers (defined as $\geq 4$ to $5 \mathrm{~cm}$ ulcers in the Japanese criteria), cobblestone appearance, and/or small aphthous ulcerations arranged in a longitudinal fashion (Fig. 2) ${ }^{5,14}$ A Korean study reported longitudinal ulcers in $37.2 \%$, cobblestone appearance in $23.9 \%$, and aphthous ulcers in $59.3 \%$ of newly diagnosed CD cases. Non-caseating granuloma, a biopsy feature suggestive of $\mathrm{CD}$, may be noted in only $13 \%$ to $36 \%$ of patients with $\mathrm{CD}$ so that sensitivity of biopsy is low. $^{15}$

Esophagogastroduodenoscopy is not routinely recommended in $\mathrm{CD}$ patients unless upper gastrointestinal symptoms are present. ${ }^{5}$ Gastroduodenal CD presents with nonspecific 

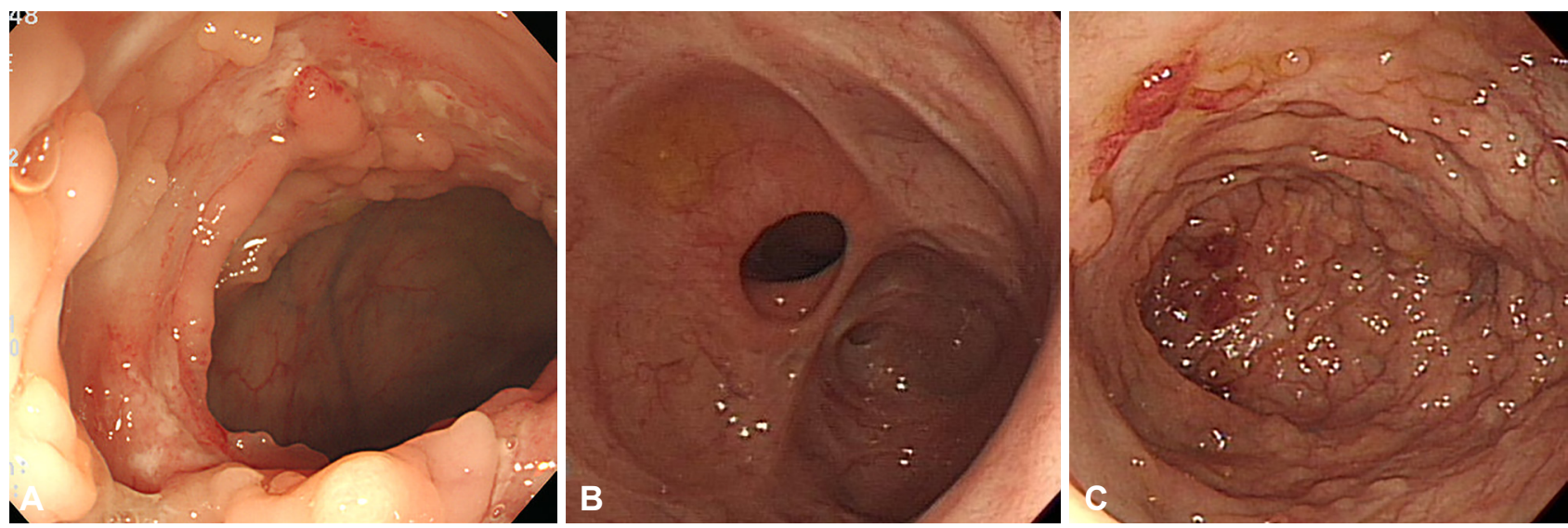

Fig. 3. Typical endoscopic features of intestinal tuberculosis. (A) Transverse ulcers, (B) deformed and patulous ileocecal valve, (C) pseudopolyps.

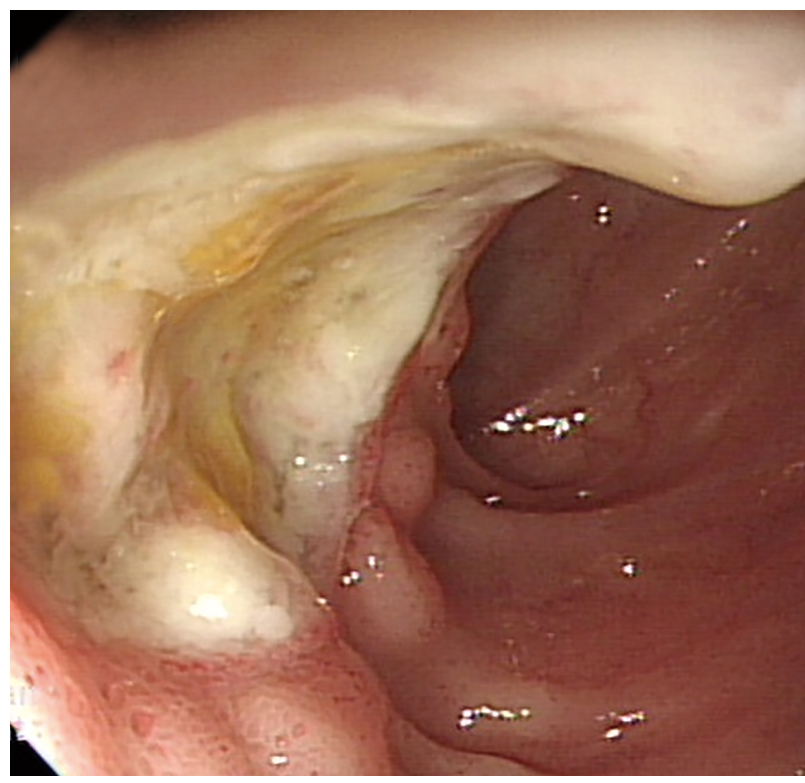

Fig. 4. Typical endoscopic feature of intestinal Behcet's disease. A large, round, deep, and discrete ulcer in the terminal ileum.

lesions such as erosions, erythema, or ulcers. ${ }^{16} \mathrm{~A}$ bamboo joint-like appearance can be seen on endoscopy, characterized by swollen, longitudinal folds traversed by erosive fissures or linear furrows on the lesser curvature of the gastric body and cardia. $^{17}$

\section{Intestinal tuberculosis}

ITB frequently involves the ileocecal area and ascending colon. Endoscopic findings of ITB may include transverse ulcers, nodules with inflammatory changes of surrounding mucosa, pseudopolyps, and/or distorted and strictured ileocecal valves (Fig. 3). 3,18,19 Although the typical histologic feature of caseating granuloma, positive acid-fast staining, and/or isolation of Mycobacterium tuberculosis from the culture of biopsy specimens can confirm ITB, these findings are present in fewer than $50 \%$ of patients. ${ }^{20,21}$ Therefore, acquisition of more than three biopsy samples from the margin and base of ulcers is recommended to increase the diagnostic yield. ${ }^{3}$

\section{Intestinal Behcet's disease}

Typical endoscopic findings in intestinal BD are a few, large, round, deep, and discrete ulcers with elevated margins in the ileocecal area (Fig. 4). Other atypical findings such as aphthous ulcers, irregular/geographic-shaped ulcers with focal distribution, and diffuse ulceration can be present in patients with intestinal $\mathrm{BD}{ }^{6,22}$

\section{DIFFERENTIAL DIAGNOSIS OF INFLAMMATORY BOWEL DISEASE}

\section{Ulcerative colitis and other causes of enterocolitis}

The differential diagnosis of UC includes infectious colitis, ischemic colitis, colitis due to drugs, radiation colitis, and solitary rectal ulcer syndrome. ${ }^{4,23}$ A history of preceding abdominal pain, medication use, radiation therapy, or straining during defecation can be helpful. ${ }^{4}$

Clinicians should always keep in mind that there is no specific endoscopic finding of UC. Infectious colitis can present with endoscopic features similar to those of UC. Thus, to make the correct diagnosis, onset and duration of symptoms should be considered together. Microbiological culture can also be helpful for differentiating UC from infectious colitis. Indeed, in a multinational web-based survey conducted by the Asian Organization for Crohn's and Colitis, more than half of Asian gastroenterologists reported always or usually performing microbiological culture for suspected UC. ${ }^{24}$

\section{Ulcerative colitis and Crohn's disease}

UC mostly presents with rectal inflammation and continu- 
Table 1. Differential Diagnosis of $U C$ and $C D$

\begin{tabular}{lcc}
\hline Characteristic & UC & CD \\
\hline Rectal involvement & Almost always & Frequent \\
Small bowel involvement & Rare & Frequent \\
Continuous lesions & Always & Infrequent \\
Depth of ulceration & Mucosa & Deeper than mucosa \\
Cobblestone appearance & No & Yes \\
Stricture & Rare & Frequent \\
Fistula & No & Frequent \\
Perianal lesions & No & Frequent \\
pANCA & ++ & + \\
ASCA & + & ++ \\
\hline
\end{tabular}

UC, ulcerative colitis; CD, Crohn's disease; pANCA, perinuclear antineutrophil cytoplasmic antibodies; ASCA, anti-Saccharomyces cerevisiae antibodies.

Table 2. Endoscopic Characteristics of CD and ITB

\begin{tabular}{lcc}
\hline Characteristic & CD & ITB \\
\hline $\begin{array}{l}\text { Involvement of ICV } \\
\text { Involvement of colon }\end{array}$ & Common & Usually, strictured and patulous ICV \\
Ulcers & $\begin{array}{c}<\text { Segments, especially terminal ileum } \\
\text { and ICV } \\
\text { Cobblestone appearance }\end{array}$ & $\begin{array}{c}\text { Longitudinal } \\
\text { and ascending colon }\end{array}$ \\
Aphtous lesions & Frequent & Transverse \\
Perianal lesions & Frequent & Rare \\
Scars/pseudopolyps & Frequent & Rare \\
\hline
\end{tabular}

$\mathrm{CD}$, Crohn's disease; ITB, intestinal tuberculosis; ICV, ileocecal valve.

ous lesions, while $\mathrm{CD}$ presents with discontinuous inflammatory lesions that frequently involve the ileocecal area. Shallow and indiscrete ulcers that involve only the mucosa, with edematous and erythematous changes in the surrounding area may suggest $\mathrm{UC}^{22} \mathrm{CD}$ can involve not only the colon but also the small bowel, and frequently presents with deep ulcers. The deep ulcers with a longitudinal array create a cobblestone appearance. Sparing of the rectum, presence of perianal disease, and occurrence of strictures and fistulas suggest $\mathrm{CD}$.

Use of serologic markers may help in the differential diagnosis of UC and $\mathrm{CD}^{25,26}$ Anti-Saccharomyces cerevisiae antibodies (ASCA) can be detected in $35 \%$ to $50 \%$ of CD patients, but in only $1 \%$ of patients with UC. ${ }^{26}$ On the other hand, perinuclear antineutrophil cytoplasmic antibodies (pANCA) are detected more frequently in patients with UC. The sensitivity of pANCA+ for UC was reportedly 55.3\%, and ASCA+ in combination with pANCA- resulted in $54.6 \%$ sensitivity for detection of $\mathrm{CD} .{ }^{25}$ Considering the relatively low sensitivity, serologic test can be the adjunctive tool when differentiation between CD and UC is clinically difficult (Table 1).

\section{Crohn's disease and intestinal tuberculosis}

The presence of longitudinal ulcers is a typical endoscopic finding in $\mathrm{CD}$, whereas transverse ulcers are common in ITB (Table 2). However, since these typical findings are not always present, it is often difficult to differentiate between the two diseases. ${ }^{23}$ In a Korean study that assessed the diagnostic value of various colonoscopic findings in CD and ITB, anorectal lesions, longitudinal ulcers, aphthous ulcers, and cobblestone appearance were seen frequently in $\mathrm{CD}$, whereas involvement of fewer than four segments, a patulous ileocecal valve, transverse ulcers, and scars or pseudopolyps were observed commonly in ITB. ${ }^{27}$ Using these parameters, the correct diagnosis was made in $87.5 \%$ of patients, with a positive predictive value of $94.9 \%$ for CD and $88.9 \%$ for ITB, respectively. However, this analysis method is still not validated, and further studies are needed.

The typical histologic finding of caseating granuloma and positive acid-fast staining are seen in fewer than $30 \%$ of ITB patients, ${ }^{28}$ but chest X-ray and interferon- $\gamma$ assay may aid in the diagnosis of ITB. In fact, $67 \%$ of ITB patients had active pulmonary TB in a Korean study. ${ }^{29}$ Therefore, chest X-ray is 
an essential test in ITB. Interferon- $\gamma$ assay may also be useful as a supplementary diagnostic tool for ITB. A recent Korean study reported that $66 \%$ of patients with ITB had a positive interferon- $\gamma$ assay (QuantiFERON-TB Gold test), compared to $9.7 \%$ of patients with $\mathrm{CD} .^{30}$

If accurate diagnosis of the two diseases remains unclear despite the above methods, performing follow-up colonoscopy after empirical anti-TB therapy can be helpful. ${ }^{3}$

\section{Crohn's disease and intestinal Behcet's disease}

A Korean study suggested an algorithm for the differential diagnosis of $\mathrm{CD}$ and intestinal $\mathrm{BD}$ according to endoscopic features. Ulcer shape, distribution, number, margins, and border contours, and the presence of aphthous, cobblestone, perianal, and strictured lesions enabled correct diagnosis of intestinal $\mathrm{BD}$ or $\mathrm{CD}$ in $92 \%$ of a study population. ${ }^{31}$ Among these parameters, the most sensitive finding indicative of intestinal BD was the absence of a cobblestone appearance, and the most specific was a round ulcer shape. In addition, distribution patterns in patients with intestinal BD are more focal than in patients with $\mathrm{CD}$. Therefore, a round ulcer or focally distributed lesions in the intestinal tract can suggest intestinal BD.

Another Korean study proposed simple criteria for the diagnosis of intestinal BD using systemic and colonoscopic features. Five or fewer lesions, oval shape, deep penetration, discrete border, and ileocecal location were regarded as typical ulcerations in BD. Overall, the positive predictive value and diagnostic accuracy using these criteria were $86.1 \%$ and $91.1 \%$, respectively. ${ }^{32}$

\section{CONCLUSIONS}

Colonoscopy is the principal test for diagnosing IBD. Clinicians can accurately diagnose most cases by fully understanding the typical endoscopic findings. In some cases, however, it is difficult to differentiate IBD due to an atypical presentation. Therefore, not only endoscopic features but also clinical symptoms, as well as laboratory, pathological, and radiological findings should be considered.

\section{Conflicts of Interest}

The authors have no financial conflicts of interest.

\section{REFERENCES}

1. Yang SK, Yun S, Kim JH, et al. Epidemiology of inflammatory bowel disease in the Songpa-Kangdong district, Seoul, Korea, 1986-2005: a KASID study. Inflamm Bowel Dis 2008;14:542-549.

2. Suzuki Kurokawa M, Suzuki N. Behcet's disease. Clin Exp Med 2004;4:1020.
3. Kim YS, Kim YH, Lee KM, Kim JS, Park YS; IBD Study Group of the Korean Association of the Study of Intestinal Diseases. Diagnostic guideline of intestinal tuberculosis. Korean J Gastroenterol 2009;53:177186.

4. Choi CH, Jung SA, Lee BI, et al. Diagnostic guideline of ulcerative colitis. Korean J Gastroenterol 2009;53:145-160.

5. Ye BD, Jang BI, Jeen YT, et al. Diagnostic guideline of Crohn's disease. Korean J Gastroenterol 2009;53:161-176.

6. Cheon JH, Shin SJ, Kim SW, et al. Diagnosis of intestinal Behcet's disease. Korean J Gastroenterol 2009;53:187-193.

7. Waye JD. The role of colonoscopy in the differential diagnosis of inflammatory bowel disease. Gastrointest Endosc 1977;23:150-154.

8. Waye JD. Endoscopy in inflammatory bowel disease: indications and differential diagnosis. Med Clin North Am 1990;74:51-65.

9. Jalan KN, Walker RJ, Sircus W, McManus JP, Prescott RJ, Card WI. Pseudopolyposis in ulcerative colitis. Lancet 1969;2:555-559.

10. D'Haens G, Geboes K, Peeters M, Baert F, Ectors N, Rutgeerts P. Patchy cecal inflammation associated with distal ulcerative colitis: a prospective endoscopic study. Am J Gastroenterol 1997;92:1275-1279.

11. Park SH, Yang SK, Park SK, et al. Atypical distribution of inflammation in newly diagnosed ulcerative colitis is not rare. Can J Gastroenterol Hepatol 2014;28:125-130.

12. Haskell H, Andrews CW Jr, Reddy SI, et al. Pathologic features and clinical significance of "backwash" ileitis in ulcerative colitis. Am J Surg Pathol 2005;29:1472-1481.

13. Stange EF, Travis SP, Vermeire S, et al. European evidence based consensus on the diagnosis and management of Crohn's disease: definitions and diagnosis. Gut 2006;55 Suppl 1:11-i15.

14. Yao T. New criteria for the diagnosis of Crohn's disease. Stomach Intest 1996;31:451-464.

15. Park JB, Yang SK, Myung SJ, et al. Clinical characteristics at diagnosis and course of Korean patients with Crohn's disease. Korean J Gastroenterol 2004;43:8-17.

16. Kang MS, Park DI, Park JH, et al. Bamboo joint-like appearance of stomach in Korean patients with Crohn's disease. Korean J Gastroenterol 2006;48:395-400.

17. Yokota K, Saito Y, Einami K, et al. A bamboo joint-like appearance of the gastric body and cardia: possible association with Crohn's disease. Gastrointest Endosc 1997;46:268-272.

18. Naga MI, Okasha HH, Ismail Z, El-Fatatry M, Hassan S, Monir BE. Endoscopic diagnosis of colonic tuberculosis. Gastrointest Endosc 2001;53:789-793.

19. Singh V, Kumar P, Kamal J, Prakash V, Vaiphei K, Singh K. Clinicocolonoscopic profile of colonic tuberculosis. Am J Gastroenterol 1996;91:565568.

20. Hoshino M, Shibata M, Goto N, et al. A clinical study of tuberculous colitis. Gastroenterol Jpn 1979;14:299-305.

21. Lee YJ, Yang SK, Myung SJ, et al. The usefulness of colonoscopic biopsy in the diagnosis of intestinal tuberculosis and pattern of concomitant extra-intestinal tuberculosis. Korean J Gastroenterol 2004;44:153-159.

22. Podolsky DK. Inflammatory bowel disease. N Engl J Med 2002;347:417429.

23. Lee HS, Choe J, Lee HJ, et al. Change in the diagnosis of inflammatory bowel disease: a hospital-based cohort study from Korea. Intest Res 2016;14:258-263.

24. Kim ES, Chen M, Lee J, Lee CK, Kim YS. Diagnosis of inflammatory bowel disease in Asia: the results of a multinational web-based survey in the 2nd Asian Organization for Crohn's and Colitis (AOCC) meeting in Seoul. Intest Res 2016;14:224-230.

25. Reese GE, Constantinides VA, Simillis C, et al. Diagnostic precision of anti-Saccharomyces cerevisiae antibodies and perinuclear antineutrophil cytoplasmic antibodies in inflammatory bowel disease. Am J Gastroenterol 2006;101:2410-2422.

26. Nikolaus S, Schreiber S. Diagnostics of inflammatory bowel disease. Gastroenterology 2007;133:1670-1689. 
27. Lee YJ, Yang SK, Byeon JS, et al. Analysis of colonoscopic findings in the differential diagnosis between intestinal tuberculosis and Crohn's disease. Endoscopy 2006;38:592-597.

28. Alvares JF, Devarbhavi H, Makhija P, Rao S, Kottoor R. Clinical, colonoscopic, and histological profile of colonic tuberculosis in a tertiary hospital. Endoscopy 2005;37:351-356.

29. Kim KM, Lee A, Choi KY, Lee KY, Kwak JJ. Intestinal tuberculosis: clinicopathologic analysis and diagnosis by endoscopic biopsy. Am J Gastroenterol 1998;93:606-609.

30. Kim YS, Kim YH, Kim WH, et al. Diagnostic utility of anti-Saccha- romyces cerevisiae antibody (ASCA) and interferon- $\gamma$ assay in the differential diagnosis of Crohn's disease and intestinal tuberculosis. Clin Chim Acta 2011;412:1527-1532.

31. Lee SK, Kim BK, Kim TI, Kim WH. Differential diagnosis of intestinal Behcet's disease and Crohn's disease by colonoscopic findings. Endoscopy 2009;41:9-16.

32. Cheon JH, Kim ES, Shin SJ, et al. Development and validation of novel diagnostic criteria for intestinal Behçet's disease in Korean patients with ileocolonic ulcers. Am J Gastroenterol 2009;104:2492-2499. 